\title{
GERMINAÇĀO E EMERGÊNCIA DE PLÂNTULAS PARA TRÊS ESPÉCIES DE GRAMÍNEAS INVASORAS DE CULTURA DO GÊNERO Digitaria HEISTER EX HALLER (1).
}

\author{
José Marcos Barbosa (2)(5) \\ Theóphilo Salem da Silva (2) \\ Roberto Andreani Junior (3) \\ Robinson Antonio Pitelli (4) \\ Luiz Mauro Barbosa (2)
}

\begin{abstract}
RESUMO - O presente trabalho relaciona a germinação de sementes com emergência de plântulas para as espécies Digitaria ciliaris (Retz.) Koel., D. horizontalis Willd. e $D$. insularis (L.) Fedde, as quais apresentam grande interesse científico e econômico por serem gramíneas invasoras muito agressivas e por apresentarem ampla distribuição geográfica na América tropical e subtropical. Os testes de germinação foram realizados mensalmente com sementes e cariopses armazenadas em câmara seca e submetidas ao processo de envelhecimento natural durante um período de 360 dias. $O$ trabalho também foi realizado para verificar o efeito da profundidade de semeadura sobre a emergência de plântulas. Os resultados de porcentagem e de velocidade de germinação das sementes mostram forte inibição da germinação causada pelas brácteas que envolvem as cariopses. Entretanto, nos tratamentos com cariopses nuas a inibição da germinação, ainda, persiste, indicando que estas sementes necessitam de um período de tempo para o amadurecimento. Os resultados de emergência de plântulas mostram que as semeaduras realizadas nas superfícies e a 2 centímetros de profundidade apresentam as mais altas porcentagens de emergências de plântulas. A interpretação dos resultados de germinação e de emergência de plântulas mostram aspectos importantes do comportamento da germinação destas espécies e permite o seu controle racional em áreas cultivadas.
\end{abstract}

Palavras chaves: Digitaria, sementes, germinação, planta invasora.

ABSTRACT - (Germination and seedling emergence for three weed grasses of the genus Digitaria Heister ex Haller). This work deals with the germination of seeds and seedling emergence of Digitaria ciliaris (Retz.) Koel., D. horizontalis Willd. and $D$. insularis (L.) Fedde and shows significant scientific and economical

(1) Trabalho desenvolvido no Instituto de Botânica com auxílio da FUNDEPAG.

(2) Instituto de Botânica, Caixa Postal 4005-CEP. 01051 - São Paulo-SP.

(3) Engenheiro Agrônomo, bolsista do CNPq.

(4) Professor Dr., Faculdade de Ciências Agrárias e Veterinárias "Campus" de Jaboticabal - UNESP.

(5) Pedidos de separatas. 
interest since the three weed grasses are very agressive and present ample geographical distribution in the tropical and subtropical American continent. The germination tests were performed monthly with seeds and caryopsis stored in a dry room or submitted to natural aging over the period of 360 days. This work was also realized to verify the effect of depth of seed planting on seedling emergence. Results of percentage and rate of seed germination showed strong inhibition of germination caused by the bracts on the caryopsis. However, in the treatments with naked caryopsis the inhibition yet persist on germination process, indicating that these seeds may require a period of after ripening. Results of seedling emergence showed that the seeds which were planted on the surface and at $2 \mathrm{~cm}$ depht gave best seedling emergence percentages. The interpretation of the results of germination and seedling emergence shows important aspects of the germination behaviour of these species and permits their rational control in cultivated areas.

Key-words: Digitaria, seeds, germination, weed grass.

\section{Introduçāo}

O trabalho apresenta um estudo sobre a germinação das unidades de dispersão e a emergência de plântulas para as espécies $D$. ciliaris (Retz.) Koel., D. horizontalis Willd. e $D$. insularis (L.) Fedde.

As gramíneas estudadas apresentam ampla distribuição geográfica na América tropical e subtropical (SILVA, 1979) e no Brasil desde o nordeste até o sul (LORENZI, 1982).

Estas espécies apresentam grande interesse científico e econômico devido aos seus mecanismos de sobrevivência e pelos prejuízos que causam à agricultura.

D. ciliaris e $D$. horizontalis são plantas anuais, com inflorescência digitadas ou subdigitadas, apresentam hábitos semelhantes e frequentemente são confundidas com $D$. sanguinalis (L.) Scop., que ocorre apenas na fronteira entre o Estado do Rio Grande do Sul e o Uruguai, segundo Cavalheiro \& Barreto (1981). Ambas são espécies heliófitas e infestam seriamente as culturas anuais, ocorrendo, também, em culturas abandonadas e outros locais alterados pelo homem. $D$. insularis é planta herbácea, perene, com inflorescência paniculada e espiguetas lanuginosas; ê também espécie heliófita, sendo mais freqüente nas pastagens e culturas abandonadas, ocorrendo sempre de forma esparsa.

O longo período de florescimento e a grande capacidade de produção de unidades de dispersão viáveis são aspectos bastante conhecidos e que contribuem para estas espécies ampliarem o seu potencial de agressividade. Apesar da grande importância que as plantas daninhas representam para a agricultura, a literatura especializada sobre estas plantas geralmente apresenta informações insuficientes no que se refere a biologia e tecnologia de sementes. ANDREANI JUNIOR et al. (1988) estudando a germinação de sementes de Cassia tora L., visando o controle desta espécies em áreas cultivadas, concluiram que a profundidade de soterramento das sementes influi na emergência de plântulas e na capacidade germinativa das sementes. Outro trabalho a ressaltar, que enfoca a 
fisiologia da germinação de sementes de espécies invasoras, foi realizado por FELIPPE \& POLO (1983) que estudaram o efeito da luz e escarificação na germinação de sementes de 31 espécies, incluindo 4 gramíneas daninhas.

No presente trabalho objetivou-se esclarecer a importância do estresse causado pelo solo sobre a germinação das sementes e , para isso, as sementes foram armazenadas em condições naturais e em câmara seca. Por outro lado, com as semeaduras em diferentes profundidades, também, procurou-se verificar a profundidade de soterramento em que as sementes apresentam maior nível de dormência $\mathrm{e}$, portanto, produzem o maior número de plântulas.

Os resultados obtidos neste trabalho permitem analisar os parâmetros: porcentagem e índice de velocidade de germinação mensal, durante um período de 360 dias, de sementes armazenadas em câmara seca e em condições de campo; porcentagem de emergência de plântulas, com semeadura em diferentes profundidades. Correlacionando os resultados de laboratório com os de campo é possível esclarecer para estas espécies os aspectos mais significativos da biologia da germinação e os mecanismos que contribuem para a perpetuação. $A$ interpretação destes resultados, também, objetiva fornecer subsídios para a área agronômica, no que se refere ao manejo integrado de plantas daninhas, conforme o proposto por FERNÁNDEZ (1982), visando um controle mais racional destas espécies.

\section{Material e Métodos}

A identificação taxọômica de cada uma das espécies estudadas foi estabelecidada com base nas descrições apresentadas por VELDKAMP (1973), SILVA (1979) e CAVALHEIRO \& BARRETO (1981). Um espécime representativo da população de cada uma das três espécies foi herborizado e depositado no Herbário do Instituto de Botânica de São Paulo (SP).

No presente trabalho é denominado de semente a unidade de dispersão, constituída por uma cariopse envolvida por glumas, lemas e pálea.

A colheita das sementes foi realizada no mês de março de 1987, na fase intermediária do período de floração das espécies, na Fazenda Santa Elisa do Instituto Agronômico de Campinas, SP. Os colmos floríferos foram coletados, conforme as recomendações de SOUZA (1981), quando apresentavam sementes com endosperma duros e com início de degrana. O processo de secagem das sementes foi realizado com os colmos dispostos horizontalmente numa caixa plástica e deixados em local arejado.

Decorrido um período de cinco dias para a secagem das sementes, os colmos floríferos foram agitados para desprender as sementes maduras (SOUZA, 1981), com as quais avaliou-se o teor de umidade, de acordo com as Regras para Análise de Sementes (BRASIL, Ministério da Agricultura, 1980). A seguir, as sementes foram separadas em dois lotes, um para o armazenamento em câmara seca, sem controle de temperatura, e outro para armazenamento em condições naturais. As sementes destinadas ao armazenamento em condições naturais foram misturadas com latossolo vermelho-amarelo fase rasa, acondiciona- 
das em doze sacos de tecido sintético poroso e enterradas a 15 centímetros de profundidade no solo do campo experimental da Seção de Sementes do Instituto de Botânica de São Paulo, SP.

A velocidade de germinação das sementes e de emergência das plântulas foram representadas, respectivamente, pelo índice de velocidade de germinação (I.V.G.) e pelo índice de velocidade de emergência de plântulas (I.V.E.), calculados de acordo com POPINIGIS (1985).

\section{a. Teste de Laboratório}

Os testes de germinação em laboratório foram efetuados a cada 30 dias, desde abril de 1987 até março de 1988.

Utilizou-se nos testes, sementes provenientes do armazenamento em câmara seca e sementes submetidas ao processo de envelhecimento natural. Os tratamentos foram realizados com 4 repetições de 50 unidades, para sementes e para cariopses, dispostas sobre papel mata-borrão dentro de caixas plásticas transparentes, medindo $11 \times 11 \times 4 \mathrm{~cm}$, e colocadas numa câmara de germinação marca "FANEM" modelo 347G. O fotoperíodo na câmara foi de 12 horas de luz num ciclo de 24 horas e a temperatura mantida constante de $25^{\circ} \mathrm{C}$. As cariopses utilizadas nos testes foram obtidas dissecando-se as sementes com pinças e estilete, sob entereomicroscópio Zeiss. As sementes colocadas para germinar foram escolhidas, pressionando-se as mesmas com estilete, para certificar a presença de cariopse. A contagem de sementes e cariopses germinadas foi realizada diariamente, durante um período de 3 semanas, considerando-se germinadas as que apresentavam plântulas com a raiz desenvolvida e com as primeiras folhas.

Durante o processo de germinação o substrato foi umedecido quando necessário.

$\mathrm{Na}$ análise estatística foram utilizados os testes de Fischer e Tuckey, em delineamento inteiramente casualizado, de acordo com GOMES (1978), e os valores em porcentagens foram transformados em arco seno $\sqrt{ } \% / 100$, segundo SNEDECOR (1976).

\section{b. Ensaio de Campo.}

Os ensaios de campo para avaliar a emergência de plântulas foram realizados em área plana e aberta no campo experimental da Seção de Sementes do Instituto de Botânica com sementes previamente submetidas ao processo de envelhecimento natural. Para $D$. ciliares e $D$. horizontalis os ensaios foram realizados no mês de março de $1988 \mathrm{com}$ as sementes que se encontravam armazenadas em condições naturais por um período de 360 dias e para $D$. insularis no mês de julho de 1987 com as sementes armazenadas por um período de 120 dias. As sementes empregadas nos experimentos foram escolhidas, pressionado-se as mesmas com estilete, para certificar a presença de cariopse.

Nos experimentos utilizou-se para cada espécie 120 sacos de polietileno, 
medindo $15 \times 30 \times 14 \mathrm{~cm}$, contendo como substrato latossolo vermelho-amarelo fase rasa.

A semeadura para cada espécie foi realizado com três sementes por saco, num total de 360 sementes, nas seguintes profundidades: $0,2,4,6$ e $8 \mathrm{~cm}$. O substrato foi irrigado antes do plantio e, a partir daí em dias alternados. $\mathrm{Na}$ análise estatística foram utilizados os testes de Fischer, empregando-se o delineamento em blocos casualizados com 4 repetições, cada uma com seis sacos plásticos, num total de 24 sacos por tratamentos (GOMES, 1978). Os valores porcentuais foram transformados em arco seno $\sqrt{ } \% / 100$ para normalização da distribuição, segundo SNEDECOR (1966).

\section{Resultados e Discussōes}

Na tabela 1 são apresentados as porcentagens dos teores de umidade das sementes e os valores médios mensais das porcentagens de germinação de sementes e cariopses obtidos nos diferentes períodos de armazenamento em câmara seca e em condições de campo. Analisando-se esta tabela nota-se que à medida que se prolonga o período de armazenamento, de um modo geral, ocorrem incrementos significativos nos valores das porcentagens de germinação de sementes e cariopses para as três espécies estudadas. Entretanto, para $D$. insularis as porcentagens de germinação de sementes armazenadas em condições de campo decrescem estatisticamente a partir do período de 210 dias quando comparado com o valor obtido no período 90 dias. Comparando-se os valores das porcentagens de germinação da tabela 1 para as sementes armazenadas em câmara seca para as três espécies, nota-se que no período inicial $D$. insularis apresenta valores muito superiores aos obtidos para as outras duas espécies. Esta superioridade no processo germinativo é confirmada pelos valores dos índices de velocidade de germinação de sementes expostos na tabela 2 , onde observa-se nitidamente a maior velocidade de germinação para as sementes de $D$. insularis no período de 60 dias.

A tabela 1 e a figura 1 mostram uma superioridade expressiva nas porcentagens de germinação das cariopses em relação a das sementes do mesmo período para as espécies de $D$. ciliaris e $D$. horizontalis, enquanto que para $D$. insularis esta superioridade é muito pequena. Ainda observa-se na tabela 1 e na figura 1 valores mais expressivos das porcentagens de germinação de sementes de $D$. ciliaris e $D$. horizontalis armazenadas em condições de campo em comparação com os encontrados para as sementes armazenadas em câmara seca, sugerindo que o estresse do solo sobre as sementes reduz a inibição causada pela presença do envoltório. Portanto, é evidente que a presença do envoltório nas cariopses causa inibição no processo germinativo das sementes, sendo mais pronunciado para $D$. horizontalis, como pode ser observado claramente na figura 1. EIRA (1983) comprova que a inibição no processo germinativo das sementes de Andropogon gayanus Kunth é devida à presença do envoltório nas cariopses e, comenta ainda, que resultados semelhantes foram observados para 
outras gramíneas, Brachiaria decumbens Stapf, B. ruziziensis Germain \& Evrard e Paspalum notatum Flügge.

Por outro lado, observa-se também na Tabela 1 e na figura 1 que os valores das porcentagens de germinação das cariopses em comparação com os das sementes de $D$. insularis não mostram uma superioridade que evidencie a inibição causada pela presença do envoltório. Entretanto, na tabela 2 os valores dos índices de velocidade de germinação evidenciam que o processo germinativo é bastante acelerado com a retirada do envoltório das sementes, inclusive para $D$. insularis.

FELIPPE \& POLO (1983) comentam que a dormência pela impermeabilidade do envoltório a entrada de água é fato comum em sementes de espécies invasoras e salientam que se trata de um importante mecanismo de sobrevivência, pelo qual as sementes podem permanecer dormentes por um período de tempo mais longo. Além da impermeabilidade, é possível ainda que a resistência que o envoltório oferece ao crescimento do embrião prejudique o desenvolvimento do processo de germinação, fato também já referido por POLLOCK \& TOOLE (1961) como sendo um mecanismo bastante comum em sementes de muitas espécies.

Observa-se ainda na tabela 1 e figura 1 que a maior porcentagem de germinação de sementes armazenadas em condições de campo ocorrem nos períodos de 300 a 360 dias, respectivamente para $D$. ciliaris e $D$. horizontalis, enquanto que para $D$. insularis o nível mais alto ocorre no período de 90 dias. Assim, os resultados das porcentagens de germinação, visualizados na figura 1, mostram que cada uma das espécies apresenta características bem típicas.

A diferenciação do processo germinativo das cariopses e sementes, nas diferentes condições de armazenamento, para as três espécies estudadas também é evidenciada na tabela 2 através dos índices de velocidade de germinação.

Analisando-se os valores dos índices de velocidade de germinação das sementes armazenadas em condições de campo (tabela 2), nota-se que $D$. insularis apresenta índices de velocidade de germinação mais expressivos em comparação com as outras espécies, principalmente, nos períodos de 60 e 90 dias e, a partir daí, decrescem significativamente. Na tabela 2 observa-se que as sementes de $D$. ciliaris e $D$. horizontalis mostram incrementos estatisticamente significativos e gradativos nos índices de velocidade de germinação à medida que se prolonga o período de armazenamento em condições de campo, evidenciando alta capacidade de germinação após 360 dias de soterramento e, por conseguinte, revelando um dos principais fatores que condiciona a agressividade nestas espéeies. Este aumento na velocidade de germinação de sementes submetidas ao soterramento é fato conhecido e já relatado por MEYER \& POLJAKOFF-MAYBER (1963).

Por outro lado, a tabela 1 mostra que ocorrem incrementos estatísticos nas porcentagens de germinação das cariopses após o período inicial de armazenamento, o que permite, ainda, evidenciar a existência de dormência primária nestas sementes. Por conseguinte, as diferentes modalidades de dormência encontradas nestas sementes podem ser interpretadas para estas espécies como um 
mecanismo de propagação mais eficiente, pelo qual sementes de um mesmo lote podem apresentar produção de plântulas por um período de tempo mais longo.

$\mathrm{Na}$ tabela 3 são apresentados os valores médios das porcentagens e dos índices de velocidade de emergência de plântulas (IVE) obtidos com semeaduras em diferentes profundidades em condições de campo. Analisando-se esta tabela, nota-se que os níveis mais altos de porcentagens e de índices de velocidade de emergência de plântulas encontram-se na superfície e a $2 \mathrm{~cm}$ de profundidade. Verifica-se ainda que de uma maneira geral os valores das porcentagens e dos índices de velocidade de emergência de plântula diminuem estatisticamente à medida que se aumenta a profundidade de semeadura. Provavelmente os resultados mais expressivos de emergência de plântulas na superfície e a $2 \mathrm{~cm}$ de profundidade estão relacionados com a maior intensidade luminosa, que promove a germinação das sementes e permite aumentar a produção de plântulas. Por outro lado, a possibilidade de emergência de $D$. ciliaris ainda com $8 \mathrm{~cm}$ de profundidade de semeadura, possibilita a esta planta uma sobrevivência maior em áreas com pertubações pelos tratamentos agriculturais.

Esta hipótese é confirmada por Ray (In FELIPPE \& POLO, 1983), que ressalta a necessidade de luz para germinação de sementes pequenas de espécies invasoras, embora, de acordo com FELIPPE \& SILVA (1984), o processo de germinação também apresenta variações em diferentes temperaturas.

$\mathrm{O}$ declínio das porcentagens de emergência de plântulas, à medida que se aumenta a profundidade de semeadura, é provavelmente devido a redução da luminosidade e ao aumento das concentrações de dióxido de carbono. Esta hipótese é corroborada por MAYER \& POLJCKOFF-MAYBER (1963), os quais se referem às altas concentrações de dióxido de carbono e as diferentes condições de iluminação como fatores que influem na germinação de sementes.

Correlacionando-se os dados de emergência de plântulas (tabela 3) com os obtidos com sementes do armazenamento natural (tabela 2) fica evidente que o soterramento mantêm as sementes dormentes e com capacidade de produzirem plântulas ao serem desenterradas, ainda que o prolongamento do período de soterramento, por mais de 90 dias (tabelas 1 e 2), para $D$. insularis reduz consideravelmente a produção de plântulas.

Portanto, o soterramento constitui um mecanismo de preservação de sementes e, também, de grande importância para perpetuação destas espécies invasoras. Para complementar o entendimento do mecanismo, é necessário evidenciar que as técnicas agrícolas aplicadas ao solo nas áreas cultivadas revolvem intensamente a terra e, consequentemente, promovem modificações na estratificação das camadas superiores, possibilitando que as sementes soterradas das espécies invasoras retornem gradualmente à superfície e produzam plântulas quando as condições ambientais forem favoráveis.

\section{Conclusōes}

1. Foram constatadas para as três espécies duas modalidades de dormência, uma de origem primária e outra devido à presença do envoltório nas cariopses. 
2. As sementes de $D$. ciliaris, $D$. horizontalis e $D$. insularis apresentaram comportamento germinativos com características bem típicas.

3. As semeaduras na superfície do solo e a 2 centímetros de profundidade mostram os níveis mais elevados de porcentagens de emergência de plântulas.

4. O soterramento constitui um mecanismo de grande importância para a perpetuação dessas espécies em áreas cultivadas.

5. Pode-se, seguramente, admitir que o controle destas espécies poderá ser realizado com maior eficiência se as técnicas aplicadas no preparo do solo e o emprego de herbicidas observarem criteriosamente as peculiaridades da biologia de germinação apresentadas por essas sementes.

\section{Referências Bibliográficas}

ANDREANI JUNIOR, R.; BARBOSA, J.M.; SILVA, T.S.; PITELLI, R.A. \& BARBOSA, L.M. 1988. Sementes de Cassia tora L. Estudo da germinação visando o controle em áreas cultivadas. Acta. Bot. bras. 1 (2): 171-177.

BRASIL, Ministério da Agricultura. 1980. Regras para Análises de sementes. Brasília, Secretaria Nacional de Defesa Agropecuária, 188p.

CAVALHEIRO, E.M. \& BARRETO, I.L. 1981. As espécies indígenas e espontâneas do gênero Digitaria Heister ex Haller (Gramineae) ocorrentes no Rio Grande do Sul. Anu. Téc. do IPZFO. Porto Alegre, 8: 171-316.

EIRA, M.T.S. 1983. Comparação de métodos de quebra de dormência em sementes de capim Andropogon. Revta. brasil. Sem. 5 (3): 37-49.

FELIPE, G.M. \& POLO, M. 1983. Germinação de ervas invasoras: efeito da luz e escarificação. Revta. brasil. Bot. 6: 55-60.

FERNÁNDEZ, O.A. 1982. Manejo integrado de malezas. Planta daninha. 5: 69-79.

GOMES, F.P. 1978. Curso de estatística experimental. 8 a ed. Piracicaba. ESALQ/USP. 430p.

JOLY, C.A. \& CRAWFORD, R.M.M. 1983. Germination and some aspects of the metabolism of Chorisia speciosa St. Hil. seeds under anoxia. Reva. brasil. Bot. 6: 85-90.

LORENZI. H. 1982. Plantas daninhas do Brasil. Edição do autor. Nova Odessa, SP. 425p.

MAYER, A.M. \& POLJAKOFF-MAYBER,A. 1963. The germination of seeds. Pergamon Press Book. New York. 236p.

POLLOCK, B.M. \& TOOLE, V.K. 1961. Afterripening, rest period. and dormancy. In Seeds: the yearbook of agriculture. Stefferud, A. ed. Washington, D.C., The united States Departament of Agriculture. p. 106-112.

POPINIGIS, F. 1985. Fisiologia da Semente. Ministério da Agricultura. AGIPLAN, Brasília, 289p.

SILVA, T.S. 1979. Espécies de Digitaria Haller dos municípios de Miranda e Corumbá. Estado de Mato Grosso do Sul. Hoehnea 8: 57-64.

SNEDECOR, G.W. 1966. Métodos estatísticos aplicados a la investigation agricola e biológica. México, Companhia Editorial Continental S.A. 626p.

SOUZA, F.H.D. 1981. Maturação e colheita de sementes de plantas forrageiras. Revta. bras. Sem. 3(1): 143-157. 
Germinação e emergência da plantulas...

VELDKAMP, J.F. 1973. A revision of Digitaria Haller (Gramineae) in Malesia, Blumea 21: 1-80. 


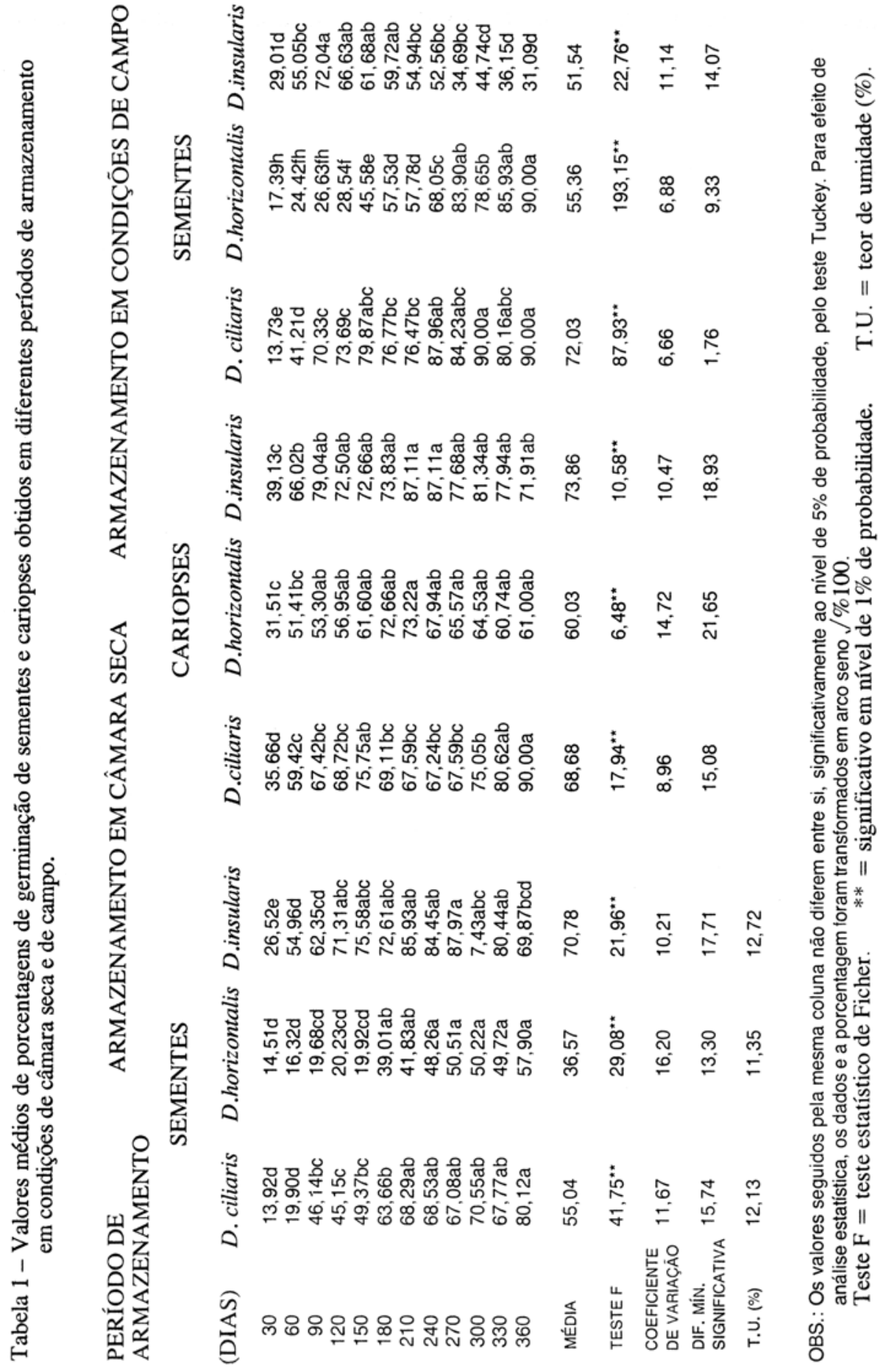




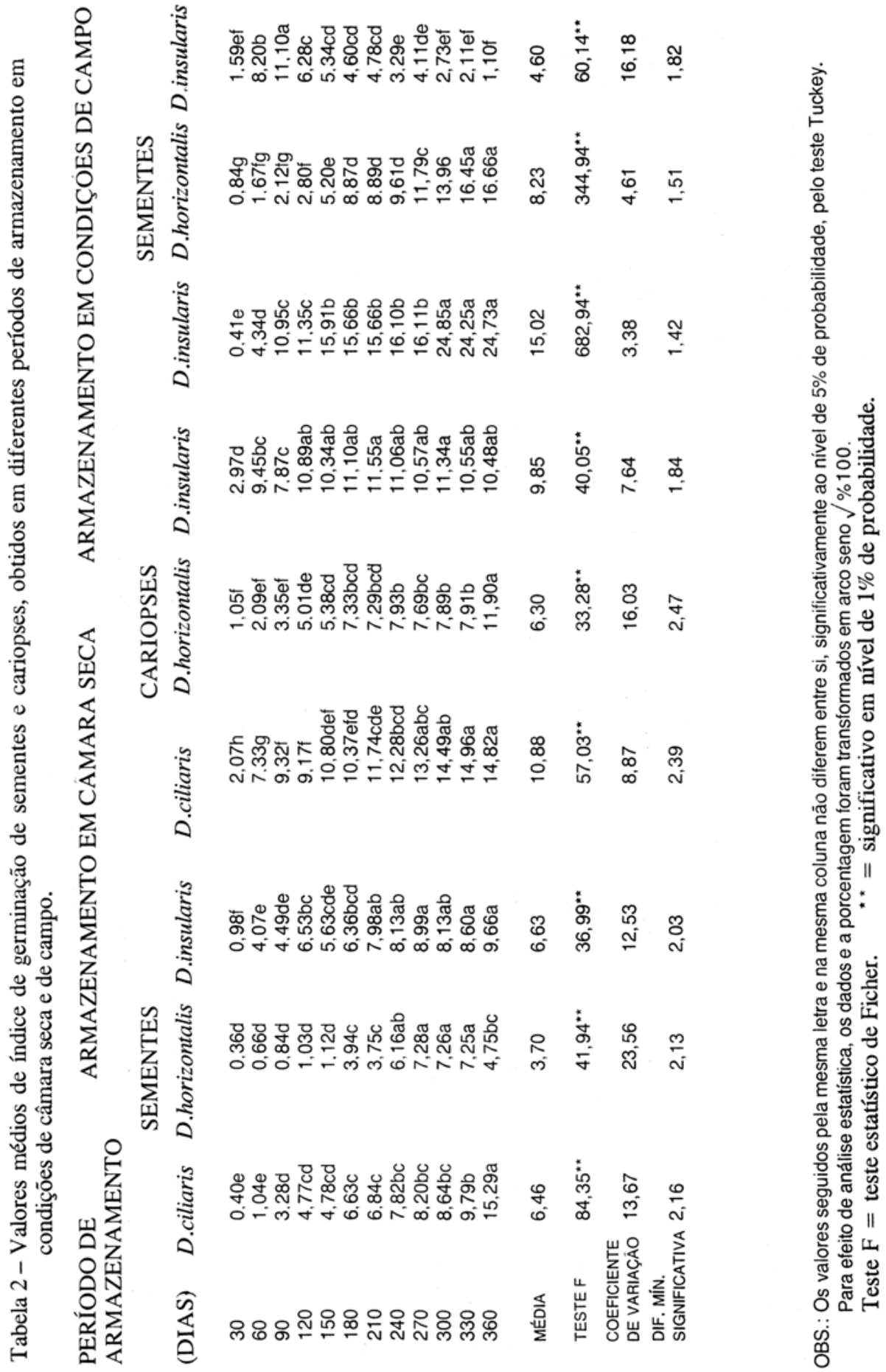




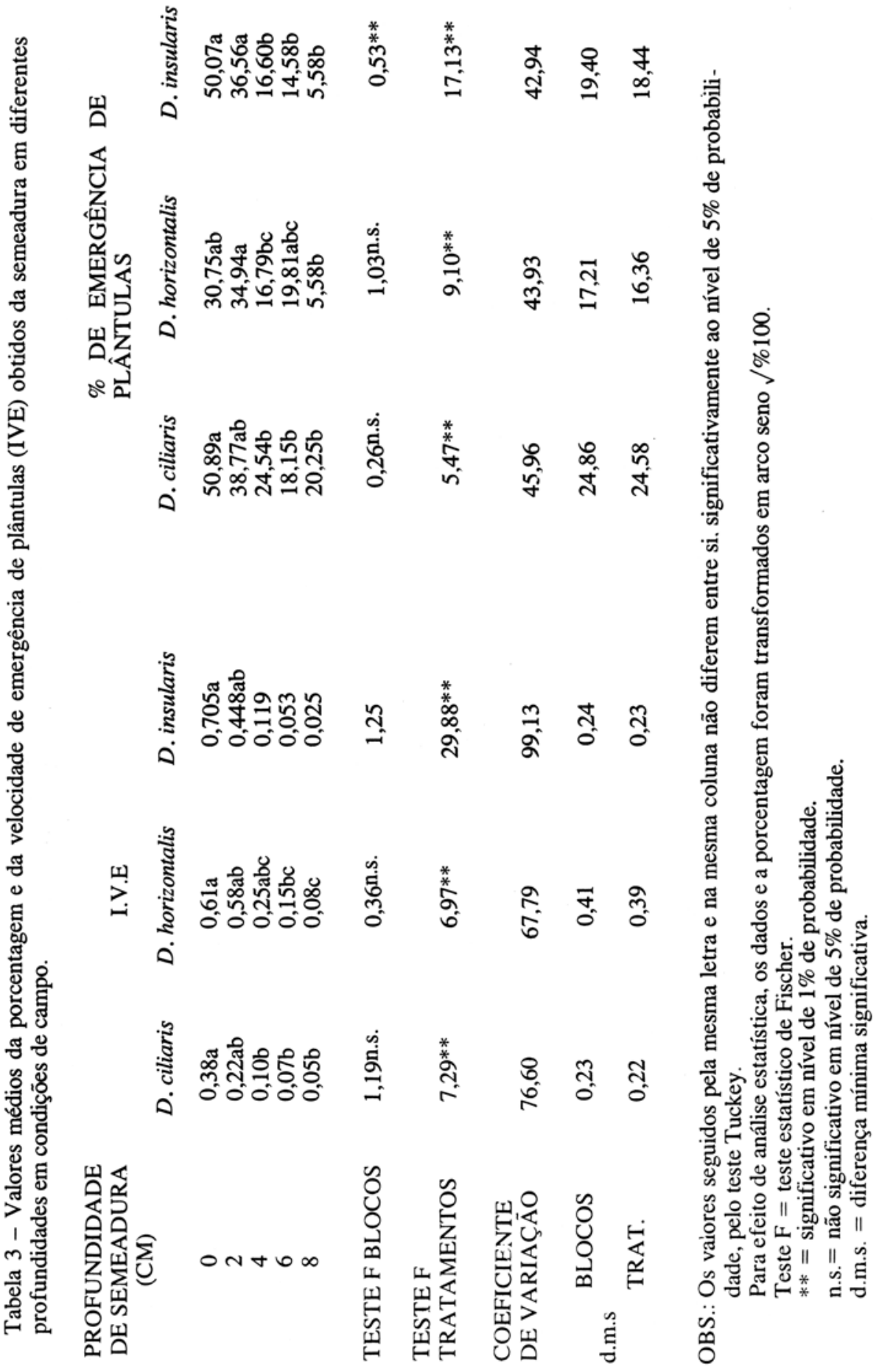




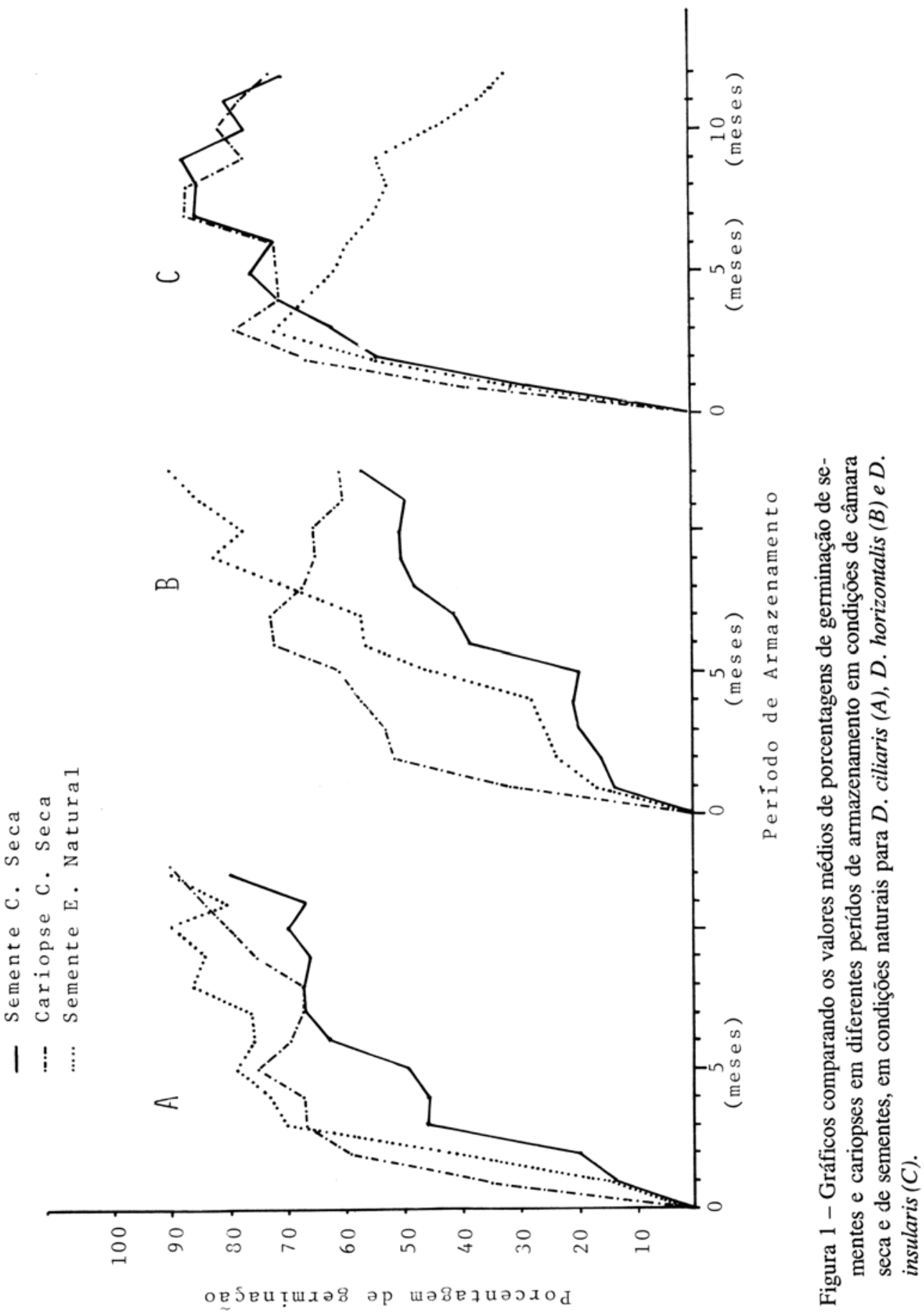

